\title{
Prosódia afetiva na esquizofrenia
}

DOl: http://dx.doi.org/10.21165/el.v49i3.2567

\section{Ana Cristina Aparecida Jorge ${ }^{1}$}

\section{Resumo}

Este trabalho consiste em um recorte da dissertação de mestrado apresentada para o Programa de Pós-graduação em Filologia e Língua Portuguesa da Universidade de São Paulo (FFLCH/USP), cuja finalidade foi efetivar uma análise automática da variação da entoação de voz de pacientes acometidos pela esquizofrenia com base no modelo ExProsodia (FERREIRA-NETTO, 2016). O estudo foi realizado a partir de duas pesquisas de campo, com 32 usuários com esquizofrenia oriundos de duas instituições de saúde mental. A esses participantes foi acrescentado um grupo de 16 pessoas sem histórico anterior de transtorno mental que compuseram um grupo de sujeitos controles. Em suma, os resultados obtidos exibem que há diferenças significativas na prosódia afetiva dos usuários com esquizofrenia em comparação com sujeitos controles.

Palavras-chaves: entoação; esquizofrenia; ExProsodia; prosódia; prosódia afetiva.

1 Universidade de São Paulo (USP), São Paulo, São Paulo, Brasil; anacristinajorge@usp.br; https://orcid.org/0000-0001-5517-9747 


\title{
Affective Prosody in Schizophrenia
}

\begin{abstract}
This paper consists of a clipping of the master's dissertation presented for the Programa of Pós-graduação in Filologia and Língua Portuguesa from Universidade de São Paulo (FFLCH/USP), whose purpose was to carry out an automatic analysis of the variation in voice intonation of patients affected by schizophrenia based on the ExProsodia model (FERREIRA-NETTO, 2016). The study was carried out based on two field researches, with 32 users with schizophrenia from two mental health institutions. To these participants was added a group of 16 people with no previous history of mental disorder who made up a group of control subjects. In summary, the results obtained show that there are significant differences in the affective prosody of users with schizophrenia compared to control subjects.
\end{abstract}

Keywords: intonation; schizophrenia; ExProsodia; prosody; affective prosody.

\section{Introdução}

Este artigo consiste em um trabalho com base nos dados existentes na dissertação de mestrado A prosódia afetiva na esquizofrenia (JORGE, 2019), cujo objetivo foi propor uma análise prosódica de pessoas acometidas pela esquizofrenia em comparação com sujeitos controles, a partir do modelo teórico aplicado pelo software ExProsodia (FERREIRA NETTO, 2016). Colaboraram com a pesquisa usuários atendidos por duas instituições de saúde mental: o Museu de Imagens do Inconsciente (MII), uma das alas do Instituto Nise da Silveira, Rio de Janeiro/RJ e o Centro de Atenção Psicossocial (CAPS) II "Espaço Vivo", uma infraestrutura dedicada ao cuidado com a saúde mental componente do Centro de Atenção Integral à Saúde Prof. Cantídio Moura de Campos, estabelecido no município de Botucatu, interior do Estado de São Paulo.

Hirst e Di Cristo (1999) explicam que, na maioria das vezes, os termos "prosódia" e "entoação" podem parecer ambíguos e/ou empregados de modo confuso. A prosódia consiste em um conjunto de fenômenos presentes no enunciado verbal. Abrange funções suprassegmentais, como a tonicidade, as pausas, os padrões rítmicos somados à entoação. Essa componente da linguagem é fundamental, já que permite o entendimento e a interpretação da mensagem emitida pelo falante para o seu ouvinte (MAUAD, 2007).

Através da prosódia são transmitidos na curva sonora fatores linguísticos, paralinguísticos e extralinguísticos. O nível linguístico envolve a diferença entre as frases afırmativas, as interrogativas e as exclamativas. O nível paralinguístico compreende a identificação das atitudes e emoções do falante a partir de elementos prosódicos. Por sua vez, o nível extralinguístico proporciona assimilar marcas relacionadas à idade, à regionalidade e ao estado de saúde do falante (MAUAD, 2007). 
Para Castagna et al. (2012), a prosódia pode ser subdividida em prosódia emocional (ou afetiva) e prosódia não emocional (ou linguística): a primeira consiste na capacidade de produzir ou reconhecer características afetivas e/ou emocional provindas de elementos prosódicos; e a prosódia linguística compreende a construção e percepção de contornos entoacionais, por exemplo, a distinção de enunciados exclamativos e interrogativos.

Conforme definido por Ferreira-Netto (2006, p. 26),

A prosódia emocional de frases caracteriza-se pela variação de tons abaixo de $1 \mathrm{KHz}$ em pontos da frase, de maneira a estabelecer uma curva melódica bem definida que os ouvintes associam a diferentes estados emocionais. Também fenômenos prosódicos menores, como duração vocálica, intensidade, pausas atuam como marcadores prosódicos capazes de expressar emoções. Trata-se, pois, de um fenômeno complexo que necessita ser avaliado como um conjunto de manifestações linguísticas cuja finalidade é expressar algum estado emocional.

No que diz respeito ao termo "entoação" existem dois níveis de ambiguidade. O primeiro lugar refere-se à maneira como a entoação está sendo definida. Em ampla acepção, a entoação compreende fenômenos lexicais como acento lexical, tom e quantidade. Em sua acepção mais restrita, descarta-se tais fatores, portanto, "entoação" se torna sinônimo de "prosódia". Em segundo lugar, é preciso o pesquisador expor os níveis de análise e descrição que serão considerados, se serão os fenômenos físicos observáveis ou a sua representação abstrata feita através de transcrições fonológicas (HIRST; DI CRISTO, 1999).

Neste artigo, considera-se a prosódia contemplando a entoação em ampla acepção, concebendo as suas manifestações físicas somando ao estudo perceptivo e às análises estatísticas dos dados. Em especial, aborda-se as variações dos parâmetros acústicos entoacionais, principalmente, a frequência fundamental, já que é vista por Hirst e Di Cristo (1999) como fator primordial de assimilação de sentido durante a transmissão da informação.

Ferreira-Netto (2016) retrata que, a partir dos estudos efetivados pelo seu grupo de pesquisas, foi possível desenvolver o software ExProsodia, o qual é capaz de promover uma análise entoacional discriminando parâmetros acústicos específicos para a frequência, a intensidade e a duração dos enunciados. Em um dos projetos desse autor, foi possível diferenciar algumas manifestações emocionais, já que o aplicativo possibilitou reconhecer que a cólera é expressa de forma mais aguda do que o tom neutro e a tristeza é transmitida em uma tonalidade grave. 
É notório o progresso dos estudos na área da entoação, no entanto, ainda há muitas possibilidades de aperfeiçoamento (HIRST; DI CRISTO, 1999). Para Behlau (2010), uma área que carece de atenção é a investigação das anormalidades prosódicas em pacientes com esquizofrenia em corpus de fala espontânea, o que poderia favorecer pressupostos diagnósticos. Ribeiro (1997) acrescenta que a linguagem verbal é uma ferramenta fundamental na clínica para identificar e caracterizar patologias.

A esquizofrenia consiste em um transtorno mental grave sem sintomatologia específica. Para o seu diagnóstico, é necessário a apresentação concomitante de pelo menos dois dos seguintes sinais ou sintomas, sendo que um é imprescindível que seja um dos três primeiros: delírios, alucinações, discurso desorganizado, comportamento grosseiramente desorganizado ou catatônico e sintomas negativos. A sintomatologia deve ser evidente pelo menos durante o período de um mês e além disso, considera-se relevante para a composição diagnóstica a apresentação de alguns sinais durante o transcorrer de 6 meses (DSM V, APA, 2013) ${ }^{2}$.

Anormalidades de linguagem em pacientes com esse transtorno mental grave não são considerações recentes; há mais de um século, Kraepelin (2004, p. 79) já considerava que "muitos doentes falam afectadamente, com uma pronúncia excessivamente acentuada, com distorção de letras isoladas e com uma entoação sem sentido".

Do mesmo modo, o psiquiatra suíço Eugen Bleuler (1960) detectou que a entoação de seus pacientes era, frequentemente, anormal. Em sua obra, esse mesmo autor descreve que apreendeu através de evidências empíricas que os pacientes com esquizofrenia exibiam uma característica entoacional singular - uma típica ausência, exagero ou um peculiar descolamento, transmitindo ao ouvinte uma ausência da manifestação emocional.

Ribeiro (1997) defende que é difícil a comunicação com uma pessoa acometida por uma psicose, já que o seu interlocutor terá que procurar por pistas implícitas nas entrelinhas do diálogo. Isso está de acordo com as considerações da psiquiatra brasileira Silveira (1992), a qual afırma que a comunicação com pacientes acometidos pela esquizofrenia é complicada, sendo que nos casos mais graves será quase nula a interação, consequentemente, os relacionamentos pessoais e interpessoais serão prejudicados.

Na pesquisa de Alpert et al. (2000), foi constatado que existem alguns pacientes com esquizofrenia que apresentam o "flat affect", isto é, uma redução quantitativa na expressão emocional através dos movimentos faciais, gestuais e entoacionais. Nesses casos, os mesmos autores explicam que, particularmente, a capacidade prosódica é afetada, os pacientes apresentam menor inflexão durante a fala.

20 Manual Diagnóstico e Estatístico de Transtornos Mentais (DSM V/APA, 2013) é um compêndio utilizado por profissionais da saúde para classificação de transtornos psíquicos e doenças mentais. 
Trémeau (2006) argumenta que pessoas com esquizofrenia sofrem prejuízos nos três principais domínios emocionais: na expressão, no reconhecimento e na avaliação da experiência emocional. Na opinião do mesmo autor, apesar de esses indivíduos possuírem a mesma compreensão semântica sobre a expressão emocional, há evidências de déficits na forma de expressão, independente do canal de transmissão, seja expressão facial ou linguagem verbal. Há maior nível de interpretação da experiência subjetiva como sentimentos de valência negativos e mais alta sensibilidade a condições de estresse. Isso prejudica a sua atuação e interação social.

\section{Procedimentos éticos}

Conforme já mencionado, este estudo é composto de duas pesquisas de campo realizadas em duas instituições de saúde mental. Portanto, em decorrência das singularidades da população analisada, houve a necessidade de alguns cuidados preliminares, os quais foram essenciais para a obtenção do resultado sem nenhuma intercorrência.

Antes de iniciar a aplicação dos projetos de pesquisa, os documentos foram encaminhados à Plataforma Brasil para apreciação ética. A pesquisa efetivada nas imediações do Instituto Nise da Silveira teve o consentimento fornecido pelo Comitê de Ética do Instituto de Psicologia da Universidade de São Paulo (IP/USP). A aprovação foi concedida através do Parecer n².065.673; emitido em 16/05/2017 às 11h27min.

Por sua vez, a metodologia aplicada no Centro de Atenção Integral à Saúde (CAIS) Professor Cantídio de Moura Campos teve parecer favorável pelo Comitê de Ética da Faculdade de Saúde Pública, autorizada através do Parecer n².301.603; em 27/09/2017 às $17 \mathrm{~h} 53 \mathrm{~min}$.

É importante salientar que os pressupostos metodológicos de coleta e análise dos dados aplicados em ambas as instituições foram os mesmos, conforme descritos na sequência.

\section{Sujeitos}

Participaram das coletas de dados: 32 usuários de instituições de saúde mental acometidos diagnosticados com esquizofrenia de acordo com os critérios do Manual de Diagnóstico e Estatístico de Transtornos Mentais, em sua $5^{\text {a }}$ edição (DSM V, APA, 2013). Desses, 16 eram usuários do Museu de Imagens do Inconsciente (doravante, SEIs) e 16 usuários do CAPS II "Espaço Vivo" (doravante, SECMs)3. Em sua maioria, os

3 Para manter o compromisso ético descrito, cada participante foi identificado com uma sigla precedida por um número cardinal. Portanto, ao longo do texto, a sigla SEls representará os sujeitos com esquizofrenia usuários do Instituto Nise da Silveira e a sigla SECMs foi utilizada para se referir aos usuários do Centro de Atenção Integral à Saúde Prof. Cantidio de Moura Campos. 
usuários estavam em tratamento ambulatorial frequente, com acompanhamento médico e psicológico na instituição de referência. Os estabelecimentos de saúde são descritos pelos usuários como elementos fundamentais para a manutenção da homeostase física e psíquica.

A estes participantes foi emparelhado um grupo de 16 pessoas sem histórico de transtorno mental ou doença psíquica que compuseram um grupo de sujeitos controle (doravante, SCs). Os critérios para a seleção desse grupo incluíam: falantes nativos do português brasileiro, alfabetizados e com nenhum histórico anterior de distúrbio psicológico e/ou psiquiátrico. A isto se soma também que foram escolhidos sujeitos com a mesma faixa etária dos participantes dos grupos com esquizofrenia (SEls e SECMs).

Os SEls eram nove participantes do gênero masculino e sete femininos; possuíam idades entre 28 e 62 anos. Os SECMs eram 13 homens e três mulheres, entre 25 e 65 anos. Por sua vez, os SCs eram nove homens e sete mulheres, com idade média de 44 anos.

A todos os participantes deste estudo foram concedidos esclarecimentos sobre os objetivos e procedimentos que seriam efetivados e sanadas quaisquer dúvidas. Sobretudo, foram garantidos o sigilo e o respeito com as informações coletadas. Os grupos aceitaram voluntariamente a participação. O Termo de Consentimento Livre e Esclarecido (TCLE) foi assinado pelos sujeitos antes do início da coleta. No caso específico de alguns usuários curatelados, o seu responsável legal também assinava, inclusive os que estão sob a tutela da coordenadora geral das instituições. Esses documentos foram impressos em duas vias, uma delas foi entregue ao participante ou a seu responsável legal e a outra foi arquivada pela pesquisadora, bem como designa a Resolução 466/12 do Conselho Nacional de Saúde.

\section{Coleta de dados}

É relevante sublinhar que durante a realização destas pesquisas não foram empregadas técnicas insalubres, invasivas ou projetivas. Os procedimentos efetivados estão de acordo com o estado clínico e mental dos usuários com esquizofrenia (SEIs e SECMs). A isto se soma que a metodologia foi empregada com o acompanhamento interno da equipe de profissionais alocada em cada instituição por meio de reuniões diárias ou semanais.

Nas duas instituições foi previsto um período em que a pesquisadora ficaria em processo de socialização antes da aplicação dos procedimentos metodológicos. Do mesmo modo que, durante a coleta de dados, a pesquisadora efetivou os procedimentos feitos com cautela para não provocar sentimentos negativos advindos dos usuários. 
A coleta de dados consistiu na gravação de um diálogo semiestruturado que originou respostas diversificadas para cada participante e pesquisadora. Os procedimentos foram efetivados com o auxílio de gravador de voz da marca H4 ZOOM. Esse equipamento foi escolhido por reter os áudios com alta qualidade e não ter um design que fosse aversivo aos participantes com transtorno mental.

Os procedimentos de coleta se dividiram em quatro etapas:

$\mathrm{Na}$ primeira foi efetivada uma entrevista de anamnese em que os participantes comentavam dados pessoais e informações relativas à sua rotina.

Na segunda, a pesquisadora solicitava que versassem sobre uma lembrança feliz e uma triste entre os seus momentos de vida.

A terceira etapa considerou que o Museu de Imagens do Inconsciente foi fundado primando por um espaço em que os usuários pudessem frequentar e realizar atividades artísticas acompanhados por um terapeuta. Os desenhos retratados poderiam ser úteis para o restabelecimento de sua homeostase psíquica. Portanto, foi previsto que os participantes descrevessem uma de suas obras, porém, como alguns não realizavam essa proposta terapêutica, foi sugerido que discorressem sobre uma ilustração ou dialogassem sobre uma obra de ficção científica de própria escolha.

Com base nas considerações de Rapcan et al. (2010), ao propor que a leitura é uma importante ferramenta metodológica com pessoas acometidas pela esquizofrenia, para finalizar, era solicitado a todos os sujeitos que lessem o mesmo trecho de uma história infantil, escolhido pela pesquisadora por ser um estrato literário neutro e sem conotação emocional. O fragmento escolhido foi o seguinte:

Quando todos estavam sentados em fila no alto do muro, olharam para baixo e viram uma cena muito estranha. À frente deles se estendia uma vasta região em que o solo era liso, reluzente e branco como o fundo de uma travessa de louça. Espalhadas por ele, havia muitas casas, todas feitas de porcelana e pintadas das cores mais vivas. As casas eram todas bem pequenas, e a maior delas mal chegava à cintura da menina. Ao lado, havia pequenos celeiros rodeados por cercas de louça, reunindo grupos de vacas, carneiros, cavalos, porcos e galinhas, todos feitos de porcelana. Mas o mais diferente de tudo eram as pessoas que viviam naquela terra estranha. Eram camponesas que tiravam leite das vacas, ou pastorinhas com vestidos de cores vivas e aventais de bordas douradas; e princesas com lindos trajes prateados, dourados e púrpura; e pastores usando suspensórios e calças curtas com listras cor-de-rosa, amarelas e azuis, e fivelas de ouro nos sapatos; e príncipes com coroas na cabeça, cravejadas de pedras 
preciosas, usando mantos de arminho e calções de seda; e palhaços engraçados com roupas enfeitadas por muitas rendas, com manchas vermelhas pintadas nos rostos e chapéus compridos e pontudos. E, o mais estranho de tudo, essas pessoas eram todas feitas de porcelana, inclusive as suas roupas, e eram tão pequenas que a maior delas não passava da altura do joelho da menina. (BAUM, 2011, p. 95).

É importante mencionar que houve quatro casos de usuários que se recusaram a ler devido a dificuldades visuais. Portanto, para a análise dos dados foram descartados quatro trechos de leitura dos sujeitos do grupo de controle.

\section{Análise dos dados}

A partir do uso dos programas de computador Adobe Audition CC 2017 utilizado para fragmentar e remover ruídos no fundo; do Speech Filing System - SFSwin (HUCKVALE et al., 1987; HUCKVALE, 2013) em correlação com a rotina de dados ExProsodia criada por Ferreira-Netto $(2008,2010,2016)$, as gravações de áudios foram transformadas em parâmetros acústicos e, na sequência, em informações estatísticas. Foi utilizado também o software Statistica para efetivar o cálculo de Análises Multivariadas por covariância, exame particularmente escolhido por verificar várias amostras ao mesmo tempo e permitir constatar as variáveis que foram mais relevantes para a obtenção do resultado gráfico. Em todas as etapas foram aferidos a média e o desvio padrão das variáveis acústicas assim como foi efetivado o cálculo da Função Gaussiana. Por fim, foi aplicado Teste F em correção com o Teste Z com o objetivo de validar ou refutar a veracidade dos parâmetros acústicos. Foram considerados representativos para ambos os testes os valores iguais ou menores que 0,05 (5\%). Porém, devido à extensão das pesquisas apresentadas neste trabalho, não foi possível expor todas as singularidades dos achados. Portanto, foi optado por demonstrar neste artigo apenas as considerações mais relevantes com o objetivo de exemplificar o exame acústico realizado durante todo o trabalho.

A ferramenta de análise de dados ExProsodia é um software elaborado por FerreiraNetto (2010), registrado pela Universidade de São Paulo (USP) no Instituto Nacional de Propriedade Industrial (INPI) (nº RS08992-2). Segundo o mesmo autor, o aplicativo ExProsodia tem como finalidade promover um exame automático dos parâmetros acústicos entoacionais do dado enunciado.

Neste estudo, foram consideradas relevantes as seguintes variáveis acústicas:

skew_F0_UBI - assimetria ou inclinação da curva da frequência;

mediana_FO_UBI - mediana da frequência; 
CV_FO_UBI - coeficiente de variação da frequência. Cálculo do desvio padrão da frequência pela média de frequência (Tom médio, TM);

kurt_FO_UBI - curtose da variação da frequência;

TM-mUBI - diferença entre o Tom Médio e o menor valor de Unidade Básica da Entoação. Esse parâmetro é obtido através do cálculo de subtração do Tom Médio pelo menor valor da Unidade Básica da Entoação;

skew_TM - assimetria do Tom Médio;

mediana_TM - valor relativo à mediana de Tom Médio;

Cv_TM - coeficiente de variação do Tom Médio. Utilizado para averiguar a dispersão. Esse parâmetro é estabelecido através do cálculo de divisão do desvio padrão do Tom Médio pelo média do Tom Médio;

dp_FEpos_UBI - desvio padrão de foco/ênfase positivo;

skew_FEpos_UBI - assimetria ou inclinação do foco/ênfase positivo;

cv_FEpos_UBI - coeficiente de variação de foco/ênfase;

kurt_FEpos_UBI - curtose de foco/ênfase.

Importante destacar que foram analisados 48 áudios, um de cada participante (16 SEls, 16 SECMs e 16 SCs). A média de gravação foi 20 a 30 minutos para cada sujeito. Durante os resultados, serão apresentados seis gráficos visando exemplificar os achados mais elementares das pesquisas efetivadas. Nas ilustrações gráficas entoacionais serão exibidas frases prototípicas, nas quais embora a informação relatada pelo participante tenha sido alterada, foi conservada a estrutura frasal. Além disso, é importante destacar que as informações coletadas foram consideradas todas em conjuntos: grupos de pacientes com esquizofrenia (SEls e SECMs) e grupo de sujeitos controle (SCs).

\section{Resultados}

\section{Anamnese}

Nessa etapa do procedimento proposto, os participantes eram convidados a mencionar aspectos individuais, como idade, grau de escolaridade e demais aspectos de suas rotinas diárias. Os usuários de ambas instituições versavam também sobre o cotidiano institucional, as atividades desenvolvidas, uso de tratamentos médico, terapêutico e farmacológico. 
Os áudios coletados foram convertidos em parâmetros estatísticos a partir da rotina de análise de dados ExProsodia, os quais serviram de base para empregar a Análise de Componentes Especiais por covariância através do software Statística. Essa técnica estatística foi especialmente escolhida por possibilitar o exame de várias amostras em conjunto. Conforme exibido no Gráfico 1, os usuários com esquizofrenia representados pela cor vermelha permaneceram mais agrupados entre si e os sujeitos controle (preto) se encontram mais dispersos no diagrama abaixo.

Gráfico 1. Anamnese - Análise de Componentes Principais por covariância (MII)

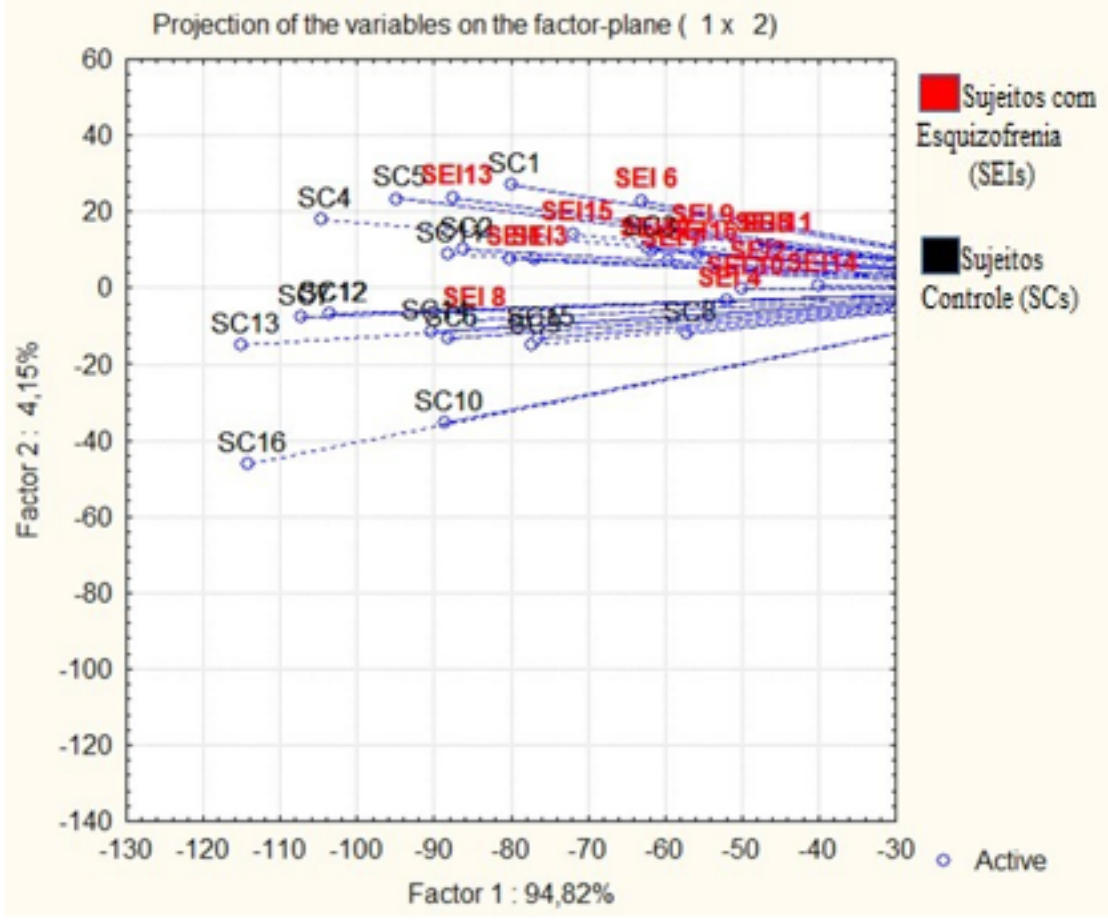

Fonte: Elaboração própria

As variáveis acústicas determinantes para a obtenção desse resultado foram no Fator 1: skew_TM; cv_TM; cv_FO_UBl; e o skew_FO_UBI.

A partir desses dados, foram retornadas as planilhas fornecidas pelo aplicativo ExProsodia. Foi selecionado o valor obtido por cada grupo para cada variável acústica e feito o cálculo da média e do desvio padrão, conforme é exibido na Tabela 1 (Gráfico 2) e Tabela 2 (Gráfico 3). É necessário acrescentar que, nas ilustrações a seguir, os SEls estão retratados pela cor azul e os SCs em laranja. 
Tabela 1. Anamnese_média (MII)

\begin{tabular}{|l|r|r|}
\hline \multicolumn{3}{|c|}{ Média } \\
\hline & \multicolumn{1}{|c|}{ SEls } & SCs \\
\hline skew_TM & $-0,057442214$ & 0,03008103 \\
\hline cv_TM & 0,09103889 & 0,135169227 \\
\hline cv_F0_UBI & 0,314744511 & 0,412102138 \\
\hline skew_F0_UBI & 0,701293024 & 1,114036768 \\
\hline
\end{tabular}

Fonte: Elaboração própria

Gráfico 2. Anamnese_média (MII)

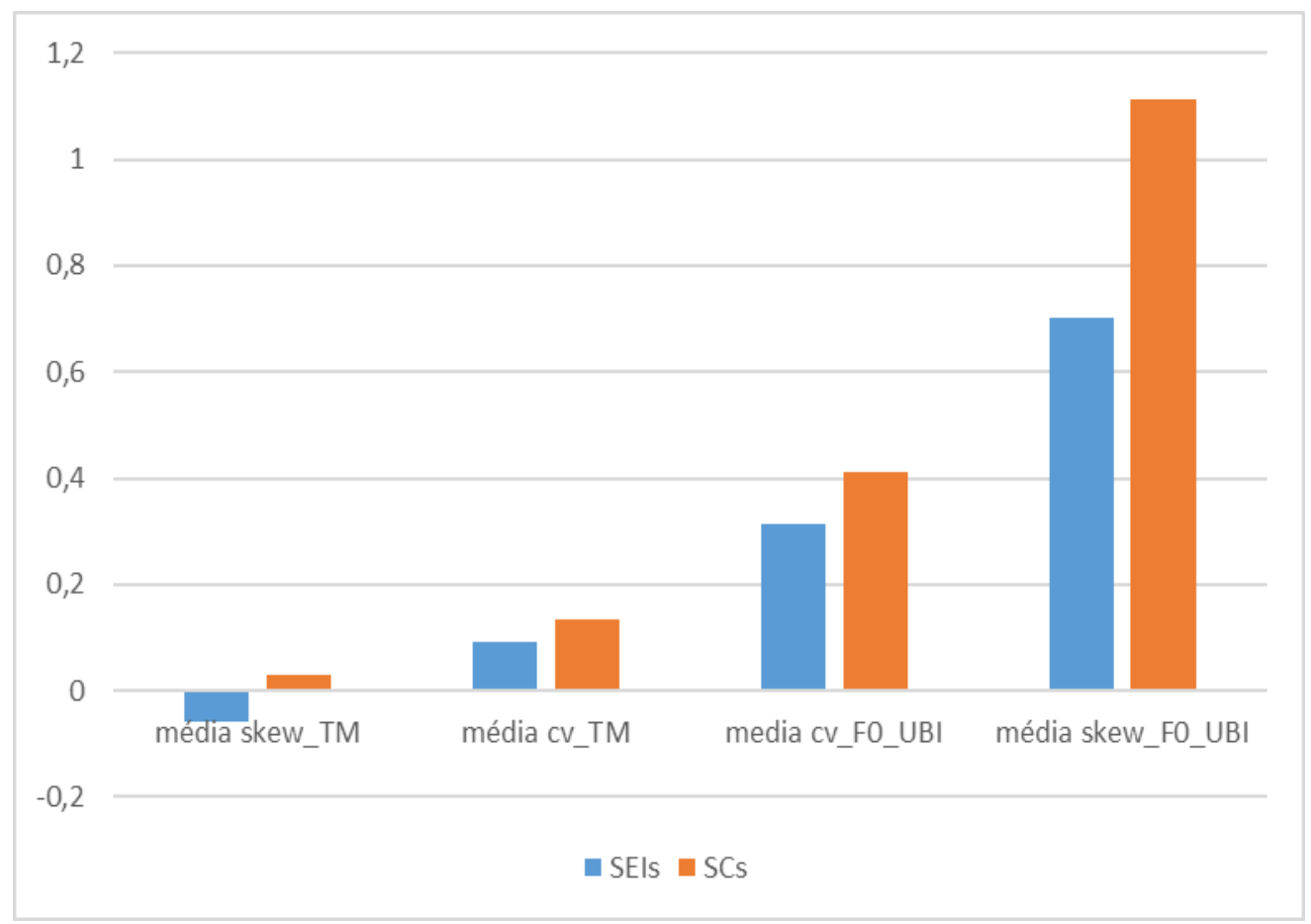

Fonte: Elaboração própria 
Tabela 2. Anamnese_dp. (MII)

\begin{tabular}{|l|l|l|}
\hline \multicolumn{3}{|c|}{ Desvio Padrão } \\
\hline & SEls & SCs \\
\hline skew_TM & 0,799487369 & 1,300436255 \\
\hline cv_TM & 0,039224433 & 0,069510771 \\
\hline cv F0_UBI & 0,091398484 & 0,161621468 \\
\hline skew_F0_UBI & 0,993738853 & 1,301895742 \\
\hline
\end{tabular}

Fonte: Elaboração própria

Gráfico 3. Anamnese_dp (MII)

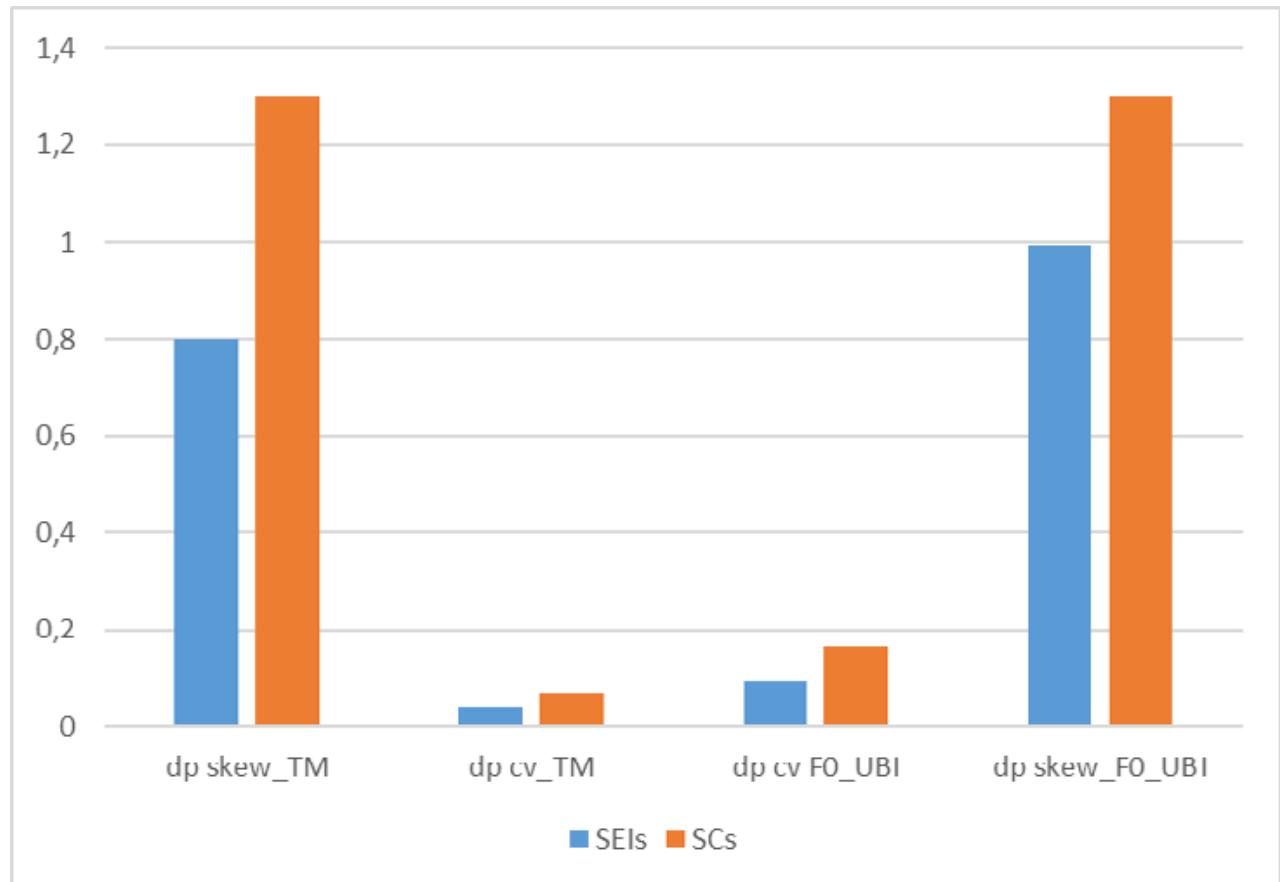

Fonte: Elaboração própria

Com base nesses resultados, é possível constatar que os valores da média e do desvio padrão exibidos nas variáveis acústicas da dispersão e assimetria pelos SEls (azul) são inferiores ao dos SCs (laranja). Isso permite sustentar a hipótese de que há menor dispersão na curva da frequência na população com esquizofrenia analisada.

Por fim, é necessário acrescentar que as variáveis acústicas que tiveram representatividade comprovada pelo Teste $F$ foram: o skew_TM $(p=0,034)$, o Cv_TM $(p=0,016)$ e o cv_F0_UBI $(p=0,017)$. Logo, para o Teste $Z$ validou o $\mathrm{cv}_{-} T M(p=0,013)$ e o CV_FO_UBI $(p=0,017)$. 


\section{Obras}

A justificativa para a criação do Museu de Imagens do Inconsciente pela psiquiatra brasileira Nise da Silveira foi a construção de um ambiente terapêutico, no qual os seus clientes tivessem a possibilidade de realizar atividades artísticas livremente e, além disso, as obras produzidas pudessem ser guardadas por longos períodos. Essas produções eram destinadas tanto ao processo terapêutico individual como à produção acadêmica. Portanto, nessa instituição todos os usuários realizam atividades artísticas. Assim, foi solicitado aos participantes que comentasse algum de seus trabalhos.

Especificamente, nesse estrato reproduzido através do Gráfico 4, o SEI 16 descreve "eu fiz um cavalo".

Gráfico 4. Obras - Curva entoacional - SEI 16 (MII)

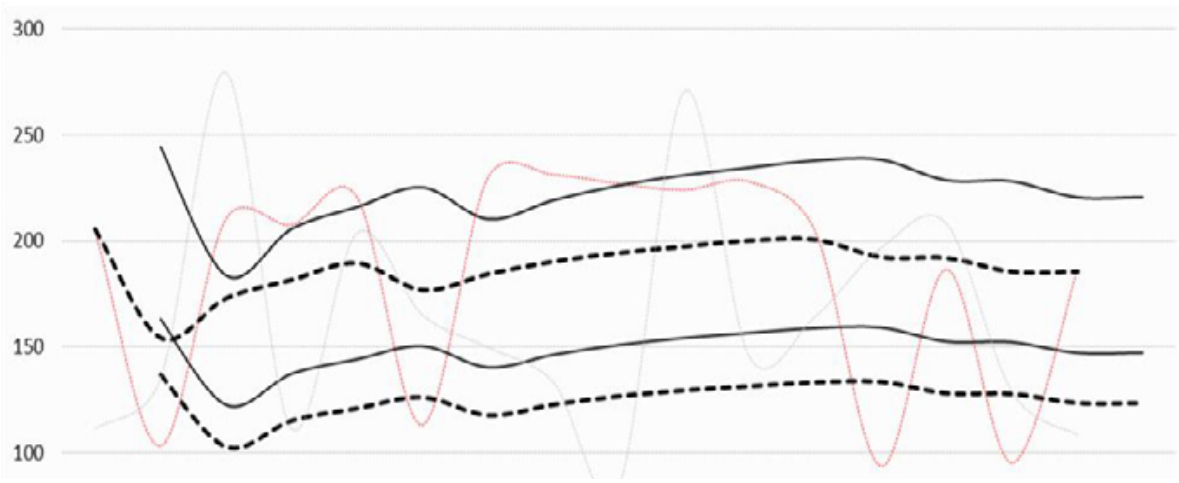

Fonte: Elaboração própria

Gráfico 5. Obras - Curva entoacional - SC 4 (MII)

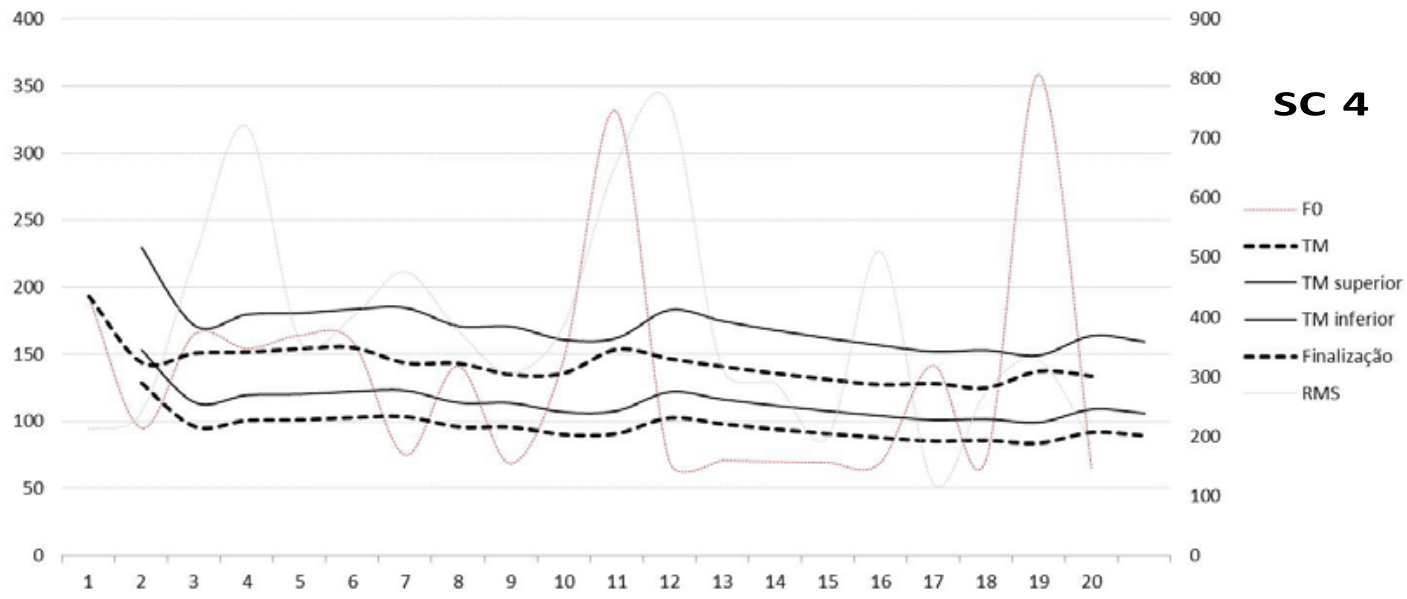

Fonte: Elaboração própria 
No Gráfico 4, é possível verificar que a linha em vermelho que reproduz a curva da frequência do usuário com esquizofrenia se mantém em sua maioria moderada entre os limites das linhas da ilustração que representam o Tom Médio Superior e Inferior. Em contraste, no Gráfico 5, observa-se que a linha vermelha que retrata a frequência entoacional durante a fala da SC4 exibe vários momentos de ênfase que se sobressaem.

\section{Relato empírico}

Nessa parte do procedimento proposto, foi requerido que os participantes versassem sobre um momento feliz e um triste entre os seus momentos de vida. Em sua maioria, os participantes se emocionaram, alguns de modo mais contido e outros de forma evidente através de risos e choro copioso.

Os Gráficos 6 e 7 exibem a curva entoacional de dois sujeitos (SECM 8 e SC7) enquanto narravam seus dramas diante da morte de um ente querido. Na opinião de SECM 8 "Foi muito triste para mim a morte da minha esposa".

Gráfico 6. Relato empírico - Curva entoacional - SECM8 (CAIS)

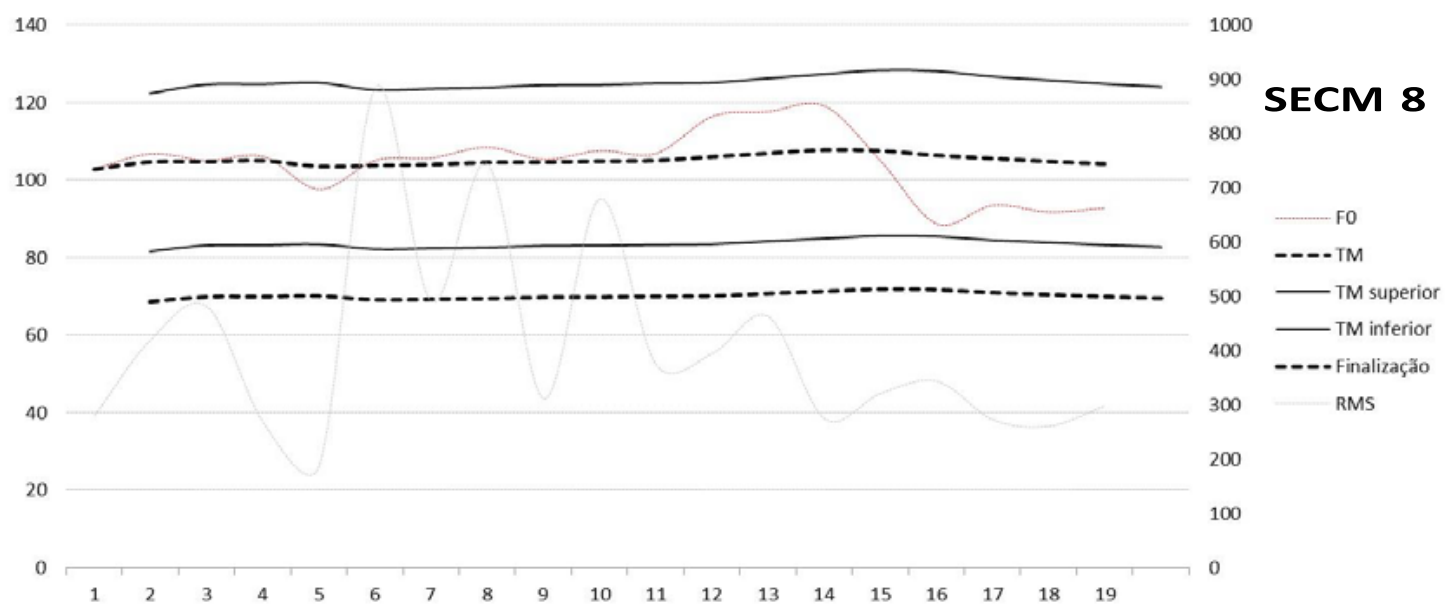

Fonte: Elaboração própria

Por outro lado, o SC7 revela que o momento mais triste de sua vida "Foi quando perdi meu pai, porque eu gostava mais". 
Gráfico 7. Relato empírico - Curva entoacional - SC7 (CAIS)

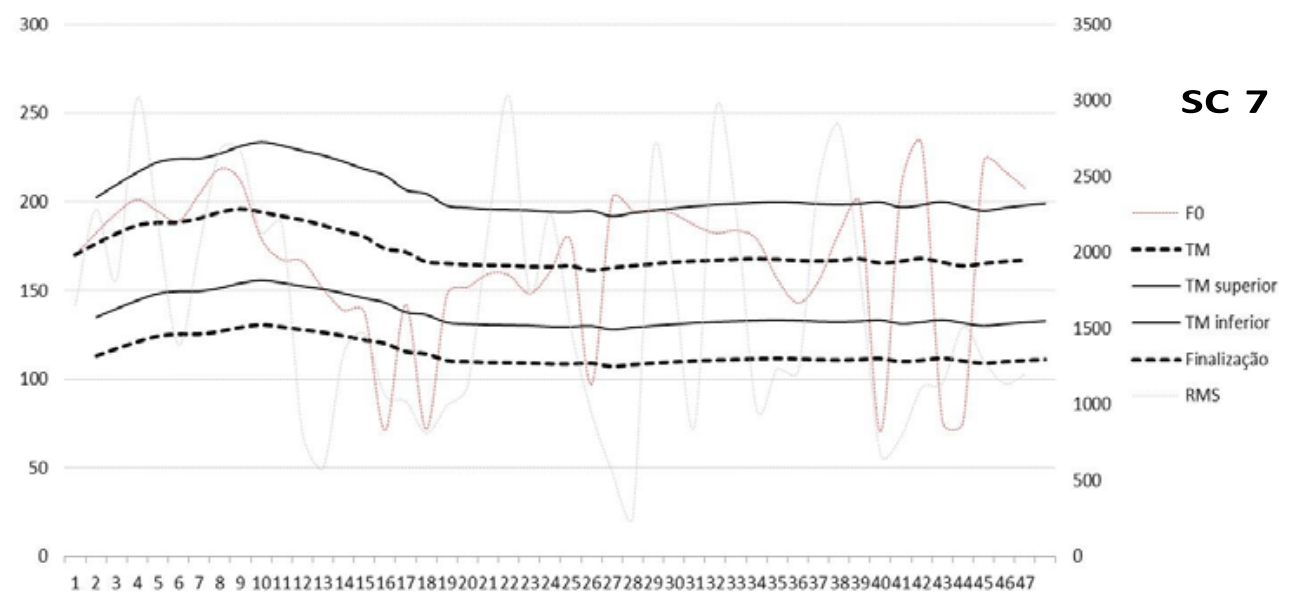

Fonte: Elaboração própria

Através dos exemplos mostrados no Gráficos 6 e 7, é possível visualizar que a linha demarcada em vermelho representa a frequência entoacional dos falantes. 0 participante com esquizofrenia apresentou menor índice de dispersão na curva, já que a linha correspondente à frequência se manteve em uma faixa que acompanha de modo contíguo as demais. Em oposição, a do sujeito controle apresenta vários momentos de foco/ênfase com maior variabilidade na curva que está ilustrada pela cor vermelha.

\section{Leitura de texto}

Para finalizar os procedimentos previstos por essa pesquisa, era solicitado a todos os participantes que lessem um trecho de uma história infantil sem conotação emocional. O Gráfico 8 ilustra o resultado do cálculo de Análise de Componentes Principais por covariância para essa etapa. 
Gráfico 8. Leitura de texto - Análise de Componentes Principais por covariância (CAIS)

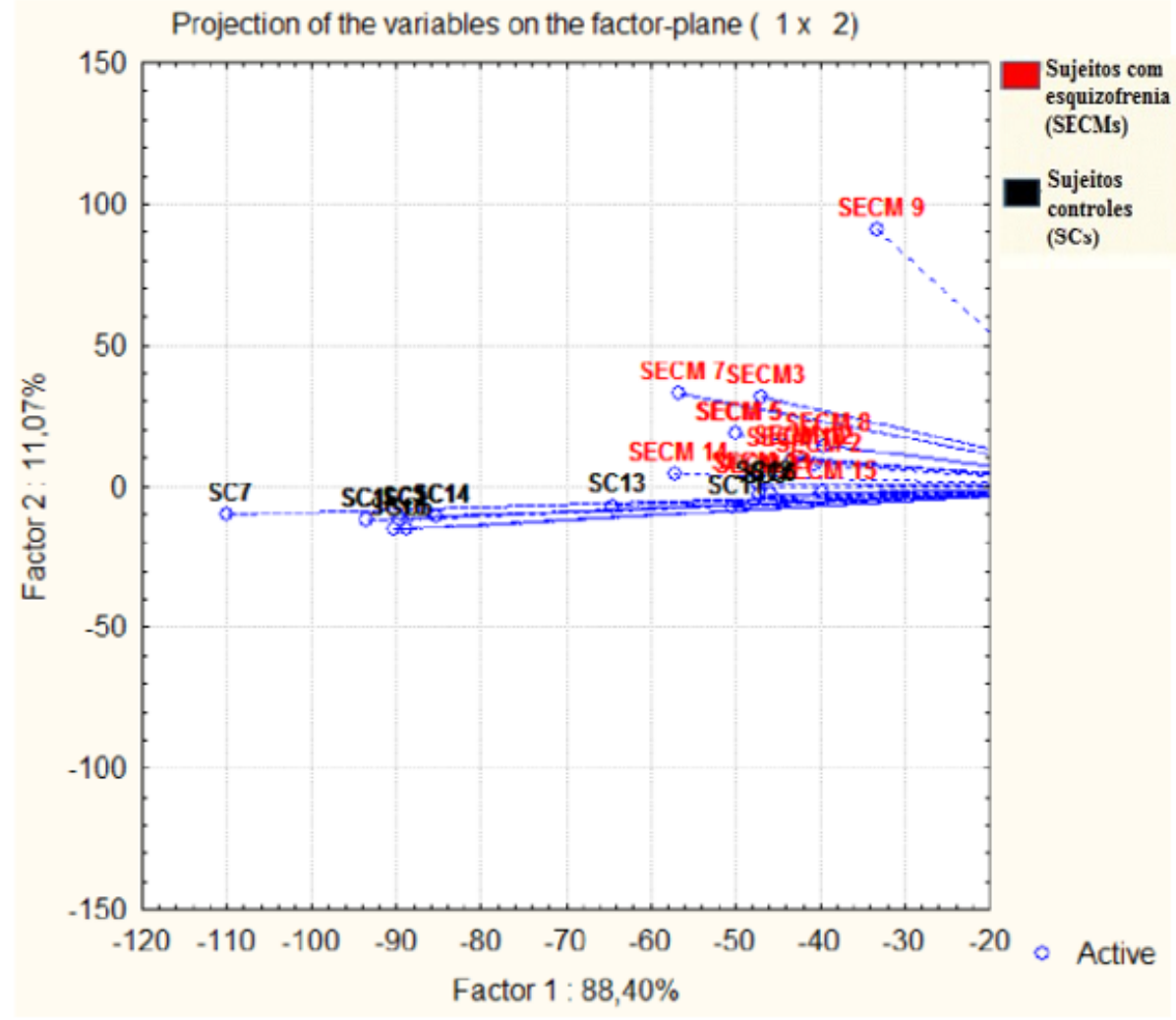

Fonte: Elaboração própria

Nessa ilustração é notório que, em sua maioria, os participantes com esquizofrenia (vermelho) se mantiveram na porção superior oposta aos SCs (preto) que estão localizados na parte inferior do Gráfico 8.

A variável acústica mais relevante para a obtenção desse resultado foi a kurt_FEpos_UBI. Os valores fornecidos pelo software ExProsodia foram novamente retomados e, com base nas informações fornecidas pelo aplicativo, foi elaborado o Gráfico 9 que representa o cálculo da Função Gaussiana. É necessário acrescentar que, nessa ilustração, os SECMs estão retratados pela cor azul e os SCs pela cor laranja. 
Gráfico 9. Leitura - Fator 2 - kurt_FEpos_UBI (CAIS)

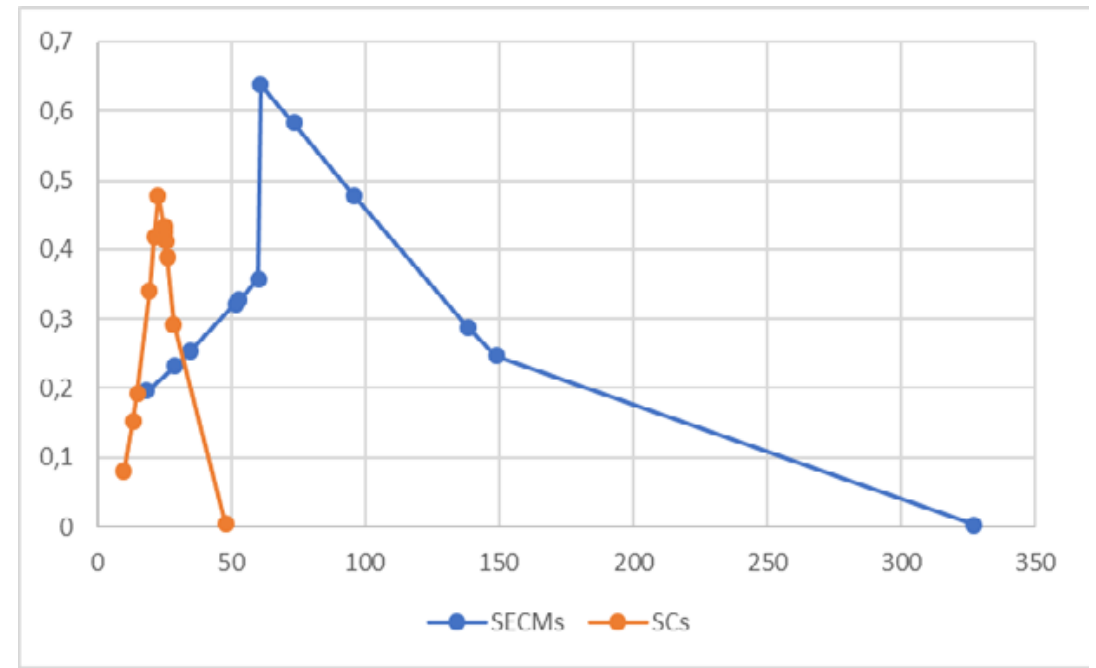

Fonte: Elaboração própria

Conforme é possível visualizar através do Gráfico 9, os valores obtidos pelos SECMs para a kurt_FEpos_UBI foram muito acentuados. Isso significa dizer em termos prosódicos que houve um achatamento singular na curva da frequência dos usuários com esquizofrenia, diferenciando-os dos SCs. Por fim, a kurt_FEpos_UBI $(p=0,002)$ teve validade comprovada através da aplicação do Teste $Z$.

\section{Considerações finais}

Este trabalho corresponde a uma síntese dos aspectos mais relevantes retratados na dissertação de mestrado Prosódia afetiva na esquizofrenia (JORGE, 2019), cujo objetivo era promover um exame automático da variação da entoação de pacientes com esquizofrenia a partir da perspectiva ExProsodia (FERREIRA-NETTO, 2006, 2008, 2010, 2016).

Os dados obtidos através desta pesquisa apontam para a perspectiva de diferenciar usuários acometidos pela esquizofrenia de sujeitos controle sem histórico de transtornos mentais ou doenças psíquicas baseado em análises prosódia. Isso permite comprovar os achados de Mota et al. (2014) ao assegurar que existe a perspectiva de um diagnóstico mais acurado para os transtornos mentais, em especial para a esquizofrenia, examinando a forma como a mensagem é transmitida.

Na etapa de anamnese, foi demonstrada uma singularidade relevante ao constatar que as variáveis acústicas da simetria e da dispersão da frequência dos SEls eram inferiores às dos SCs. Isso corrobora a pesquisa de Tavano et al. (2008) que afirmou que, independente da metodologia aplicada, serão constatadas reduções significativas da diversidade e da fluência da fala em pessoas com esquizofrenia. 
Nas etapas de Obras e Relato Empírico empreendidas por esta pesquisa, foram encontradas diferenças significativas, em especial a entoação apresentada pelos SEls e SECMs permanecia moderada pelos limites do Tom Médio com breves momentos de foco/ênfase ao oposto dos sujeitos saudáveis que apresentavam picos de ênfase que se sobressaiam na faixa do Tom Médio. Esse resultado é similar aos achados descritos por Alpert et al. (2000) ao retratar que indivíduos com esquizofrenia exibem em sua entoação de voz uma redução quantitativa na expressão da emoção. As mesmas considerações também são propostas por Martins e Ferreira-Netto (2017) ao discorrem sobre o Simulacrum of Neutral Intonation (SNI) que ocorre em momentos de estresse intenso ou em casos de algumas patologias, por exemplo, a esquizofrenia.

Na última etapa, a de Leitura de Texto, destaca-se em particular o papel relevante da variável acústica kurt_FEpos_UBI, já que em decorrência dos valores excessivamente altos obtidos pelos SECMs houve um achatamento singular da curva da frequência. Isso comprova o argumento de Rapcan et al. (2010) ao constatar que tarefas baseadas na leitura de um texto são ferramentas úteis na identificação da esquizofrenia.

É notório que tais achados poderiam auxiliar em um diagnóstico mais conciso para a esquizofrenia e outros transtornos mentais. Poderiam também ser úteis como um componente importante durante a avaliação e/ou adequação ao tratamento. A entoação é a característica mais particular dos seres humanos a partir da qual é viável considerar aspectos relevantes que viabilizem identificar o processo psicopatológico.

\section{REFERÊNCIAS}

ALPERT, M. et al. Prosody and lexical accuracy in flat affect schizophrenia. Psychiatry Research, n. 97, p. 107-118, out. 2000.

AMERICAN PSYCHIATRY ASSOCIATION. Diagnostic and Statistical Manual of Mental disorders - DSM-5. 5th.ed. Washington: American Psychiatric Association, 2013.

BAUM, L. F. O mágico de Oz. São Paulo: Leya, 2011.

BEHLAU, M. Voz: o livro do especialista. v. II. Rio de Janeiro: Revinter, 2010.

BLEULER, P. E. Demencia precoz: el grupo de las esquizofrenias. Tradução Daniel Ricardo Wagner. Buenos Aires: Editorial Paidós, 1960.

BRASIL. Ministério da Saúde. Portaria n 336/02, de 19 de fevereiro de 2002. Brasília: Ministério da Saúde, 2002. Disponível em: http://portal.saude.go v.br/portal/arquivos / pdf/Portaria\%20GM\%20336-2002.pdf. Acesso em: 10 ago. 2019. 
CASTAGNA, F. et al. Prosody recognition and audiovisual emotion matching in schizophrenia: The contribution of cognition and psychopathology. Psychiatry Research, n. 205, p. 192-198, fev. 2012.

FERREIRA-NETTO, W. Variação de frequência e constituição da prosódia na Língua Portuguesa. 2006. Tese (Livre Docência) - Faculdade de Filosofia, Letras e Ciências Humanas, Universidade de São Paulo, São Paulo, 2006.

FERREIRA-NETTO, W. Decomposição da entoação frasal em componentes estruturadoras e em componentes semântico-funcionais. In: CONGRESSO NACIONAL DE FONÉTICA E FONOLOGIA/CONGRESSO INTERNACIONAL DE FONÉTICA E FONOLOGIA, X/IV. Niterói, 2008. Disponível em: http://www.academia.edu/2272651/ Decomposicao_da_entoacao_frasal_em_componentes_estruturadoras_e_semanticofuncionais. Acesso em: 20 ago. 2019.

FERREIRA-NETTO, W. ExProsodia: Resultados preliminares. São Paulo: Ed. Paulistana, 2016 .

FERREIRA-NETTO, W. ExProsodia. Revista da Propriedade Industrial - RPI, 2038, item 120, em 26 out. 2010.

HIRST, D.; DI CRISTO, A. (org.). Intonation Systems. Cambridge: Cambridge University Press, 1999.

HUCKVALE, M. A. Speech Filing System v.4.7/Windows SFSWin Version 1.9, em: 18 abr. 2013. Disponível em: http://www.phon.ucl.ac.uk/resource/sfs. Acesso em: 20 ago. 2019.

HUCKVALE, M. A. et al. The SPAR Speech Filing System. In: European Conference on Speech Technology, Edinburgh, 1987. Disponível em: http://www.phon.ucl.ac.uk/home / mark/papers/sparsfs87.pdf. Acesso em: 20 ago. 2019.

JORGE, A. C. A. Prosódia afetiva na esquizofrenia. 2019. Dissertação (Mestrado) Faculdade de Filosofia, Letras e Ciências Humanas, Universidade de São Paulo, São Paulo, 2019.

KRAEPELIN, E. A demência precoce $7^{a}$ parte. Tradução Dra. Virgínia Ramos. Lisboa: Editora Climepsi, 2004. 
MAUAD, S. A. Questões de prosódia: uma investigação, com apoio de instrumentais de análise fonético-acústica, dos padrões entoacionais de falantes bilíngues brasileiros e norte-americanos. 2007. Dissertação (Mestrado em Linguística Aplicada e Estudos da Linguagem) - Pontifícia Universidade Católica de São Paulo, São Paulo, 2007.

MARTINS, M. V. M.; FERREIRA-NETTO, W. Proposal of description for an intonation pattern: The simulacrum of neutral intonation. The Journal of the Acoustical Society of America, n. 141, p. 3701, 2017.

MOTA, N. et al. Graph analysis of dream reports is especially informative about psychosis. Scientific Reports, 4:3691, jan. 2014.

RAPCAN, V. et al. Acoustic and temporal analysis of speech: a potential biomarker for schizophrenia. Medical Engineering and Physics, v. 32, n. 9, p. 1074-1079, jul. 2010.

RIBEIRO, B. T. Análise de enquadres em uma entrevista psiquiátrica. In: RIBEIRO, B. T. O discurso em Mosaico: contribuições da Linguística para o campo da saúde mental. v. 1. n. 1, Rio de Janeiro: UFRJ, 1997.

SILVEIRA, N. da. O mundo das imagens. Rio de Janeiro: Ática, 1992.

TAVANO, A. et al. Specific linguistic and pragmatic deficits in Italian patients with schizophrenia. Schizophrenia Research, v. 102, p. 53-62, abr. 2008.

TRÉMEAU, F. A review of emotion deficits in schizophrenia. Clinical Research: Dialogues in Clinical Neuroscience, v. 8, p. 59-70, n. 1, 2006. 